\title{
Meu Irmão Adauto
}

\author{
Ethel V. Kosminsky*
}

Para Nete Lima, minha sobrinha querida Em memória de Abrahão Kosminsky, pai, avô e bisavô.

Em abril de 2015, fui visitar o meu irmão Adauto pela primeira vez. Ele com 85 anos e eu com quase 69. Ele morando em Vitória da Conquista, Estado da Bahia, e eu em Nova York, Estados Unidos. Foram 3 longos voos não só pela distância, como também pela ansiedade.

Há cerca de 15 anos o meu irmão mais novo, Nilton, perguntou à nossa mãe se ela sabia da existência de um filho de nosso pai. O nosso pai Abrahão havia falecido em 1971, há muito anos. Estávamos nós, os três filhos, incluindo Doris, a caçulinha, visitando a nossa mãe, que morava no Rio de Janeiro. Ela, entre surpresa e aborrecida, negou de modo veemente. Assim, essa história desapareceu da minha mente.

Em dezembro de 2014, Doris recebeu uma mensagem do neto de Adauto, Malone, que mora em Aracajú, Sergipe, e estava visitando o avô em Vitória da Conquista. Malone encontrou a Doris pelo Facebook. Conversou com ela e pediu que ligasse pelo Skype para o avô no dia do Natal. Então, usando da prerrogativa da primogenitura, eu assumi essa tarefa. Estava curiosa e ansiosa ao mesmo tempo e queria de uma certa forma retomar o contato com o nosso pai através do filho mais velho. De imediato aceitei a ideia de ter um irmão mais velho por parte de pai.

Pensei no Prof. Walter Rehfeld, que foi meu professor sobre o Antigo Testamento como literatura, na Universidade de São Paulo, quando fazia meu mestrado em Sociologia. Durante um semestre estudamos o sacrifício de Isaac. Rehfeld, um mensch ${ }^{1}$, uma pessoa íntegra e honrada, ensinou-me a prática da Mitzvá, um preceito judaico que ele definia como a prática simultânea da justiça e da caridade, no sentido de amor pela humanidade.

Essa foi a motivação inicial para a minha ida a Vitória da Conquista. Pensei, se o meu pai houvesse deixado de assumir a sua obrigação, eu iria de certo modo repará-la. Uma ideia que, depois constatei, não iria fazer sentido algum. Nete, a minha sobrinha, filha de Adauto, disse: "Ethel, se Abrahão sabia ou não, não interessa, o que importa somos nós agora".

\footnotetext{
* Professora Livre-Docente de Sociologia do curso de Ciências Sociais da Universidade Estadual Paulista-UNESP - Campus de Marília (Aposentada). Professora adjunta de Sociologia do Queens College/CUNY (2008-2013).
} 
Nosso pai devia ter 15 anos na época em que Adauto nasceu. Não morava mais no Recife. Já seus pais, irmãos e avós ainda moravam na cidade, na rua dos Coelhos, no primeiro andar de um prédio pobre. $\mathrm{O}$ avô Maurício, seu pai, vendia tecidos à prestação, como muitos judeus e sírio-libaneses faziam.

Abrahão se recusou a seguir a ocupação do pai. Gostava de desenhar e de pintar. Foi trabalhar como desenhista no Departamento Nacional de Obras Contra as Secas (DNOCS) do governo federal, no interior da Paraíba, na construção de açudes. De vez em quando, vinha visitar a família. Bela, sua irmã caçula, e a única viva ainda, disse que "cada vez que ele chegava era uma festa".

Os pais e avós de Abrahão chegaram no Brasil em 1913. Vieram com outras famílias da Bessarábia, hoje Moldava. Desembarcaram na llha das Flores, no Rio de Janeiro. De lá pegaram o trem para a colônia de Quatro Irmãos, situada entre Erechim e Passo Fundo, no Rio Grande do Sul.

A colônia foi fundada pelo Barão von Hirsch ${ }^{2}$, com a intenção de promover a emigração da Europa Oriental de judeus pobres, vítimas dos pogroms ${ }^{3}$, ataques violentos promovidos por $\operatorname{cossacos}^{4}$ no antigo Império Russo. Além de ajudar as vítimas, Hirsch tinha interesse em desenvolver a produção de trigo para exportação. Desse modo, fundou colônias no Rio Grande do Sul e na Argentina.

No entanto, Quatro Irmãos fracassou. Não houve o apoio financeiro necessário. Muitas famílias foram para as cidades de Santa Maria e de Porto Alegre. Os Kosminsky mudaram-se para o Recife, provavelmente, porque alguns parentes já estavam trabalhando e morando lá.

O avô de nosso pai Abrahão, lossi (José) Kosminsky, e sua avó Shenda (Sonia) trouxeram os 10 filhos, todos solteiros. No mesmo navio da Bessarábia veio a família Milman. O primogênito, Mauricio (Moishe) Kosminsky, casou-se com a mais velha entre os filhos dos Milman, Eidel, ainda em Quatro Irmãos.

Ela deu a luz a Abrahão em 1914, uma criança loura de olhos azuis, diferente das outras pessoas da família Kosminsky que tinha cabelos e olhos escuros. Eidel e o segundo filho morreram durante o parto. De acordo com Sara Soibelman, tia de Abrahão, o médico da colônia era péssimo. Assim, nosso pai foi criado por tia Sara e sua avó maternal, Clara Milman.

O segundo casamento de Mauricio foi com Rosa Litvin na casa da avó Clara. Ela queria saber para quem entregaria o neto. Nunca conseguimos achar uma foto de Eidel Kosminsky. Abrahão nunca conheceu a mãe. Seguindo o costume dos judeus da Europa Oriental, nosso pai deu-me o nome de Ethel em homenagem à Eidel.

Cheguei em Salvador em um sábado, meia-noite e meia, No aeroporto estavam minha sobrinha mais velha, Nete, e duas de suas amigas. Fui imediatamente abraçada, filmada e fotografada pela minha nova família. Estávamos muito felizes de nos vermos pela primeira vez. Fomos para a sua casa em Jauá comemorar o aniversário de seu marido, o Lazinho. Na segunda iríamos sair cedinho para Vitória da Conquista de avião. 
Acho que comer com a família aumenta o apetite e traz felicidade, como dizem antropólogos e sociólogos da área de alimentação. Assim comi dois pratos de feijoada e ainda um pouco de rabada. Como fui criada em Salvador, estava também respondendo à saudade de infância e juventude. Comer é um ato social e cultural ao mesmo tempo.

A chegada em Vitória da Conquista foi carregada de emoção. Meu irmão Adauto e eu nos abraçamos e choramos ao mesmo tempo. Dalva, sua esposa, minha cunhada, comentou filosoficamente: "Até as pedras se encontram. Esse encontro deveria ter acontecido há 20 anos, quando tínhamos saúde". Eu respondi, o importante é que aconteceu.

Aos poucos fui conhecendo toda a família: seus filhos, meus sobrinhos... Pat, a caçula, que havia nos buscado no aeroporto com seu lindo filho Pedroca, de 9 anos; seu marido Pierre; o mais velho de todos os filhos de Adauto, Ivanildo, e sua esposa Ari; Tici, a filha de Ivanildo do primeiro casamento; Toni Zé, sua esposa Petta e o filho Lucca.

Meus preparativos para a viagem consistiram em escolher um quadro de Abrahão, que tinha sido professor de desenho artístico da Escola de Belas Artes da Universidade Federal da Bahia e arquiteto, formado pela Faculdade de Arquitetura da mesma universidade. Quando graduou-se em arquitetura, eu já tinha 12 anos. Escolhi uma paisagem de árvores, troncos e folhagens em tons impressionistas, como a escola francesa de pintura que ele gostava. Esse seria o presente mais importante que levei para Adauto. Além disso, comprei para meu irmão e esposa sweaters de algodão. Infelizmente escolhi números muito grandes.

Depois do jantar, sentava em uma cadeira no quarto dos dois para continuar a conversa. Adauto sentia muito frio devido às sessões de quimioterapia. Enrolava-se todo em um cobertor na cama, com Dalva ao lado. Minha cunhada havia quebrado o ombro em duas partes em uma queda, consequência da osteoporose. Estava com o ombro imobilizado.

O nosso passado se intercalava com o presente. Gravei partes dessas conversas, menos as que fazem mal ao coração. Adauto estudou como interno no colégio dos Salesianos no Recife. São muito católicos. Nas paredes da sala tem uma pintura da Santa Ceia e um desenho da cabeça de Jesus Cristo. E agora a pintura do pai Abrahão foi reunida aos desenhos sacros. Eu disse para Nete que a Santa Ceia é como os judeus costumavam se sentar no início do Shabat ${ }^{5} \mathrm{e}$ como ainda se sentam em algumas sinagogas para dividirem pão e vinho. Pensei, como seria bom se houvesse uma única religião no mundo. Será que haveria mais paz?

O Catolicismo não me era estranho. Tinha sido criada em uma rua estreita no bairro de Brotas, em Salvador, onde todos se conheciam. A maioria dos vizinhos era católica. Havia também uma família espírita e uma protestante. 
Nosso pai não queria que nos sentíssemos diferentes das crianças cristãs. Todo o Natal, quando acordávamos, encontrávamos presentes em nossos sapatos e íamos para a rua brincar. Tinha um desejo de ser igual aos outros, ser católica também. Éramos a única família judia daquela rua.

Fui criada pela empregada de minha mãe, que frequentava um terreiro de candomblé. Nunca me esqueço que, quando passei no exame de admissão ao ginásio, ela preparou um caruru de São Cosme e São Damião, os santos crianças que faziam parte da Igreja Católica e do Candomblé. A mesa estava arrodeada das crianças vizinhas. A minha mãe tinha viajado para cuidar da sua irmã que estava muito doente. Até hoje tenho São Cosme e São Damião em casa.

Trouxe uma fotocópia do convite de formatura de Abrahão em arquitetura e um artigo do jornal "A Tarde", de Salvador, em que um ex-aluno da Escola de Belas Artes elogiava o trabalho dele e a maneira atenciosa com que tratava os estudantes. Todas as informações e imagens passaram de mão em mão.

Mostrei fotos de lossi (José) e Shenda (Sonia) Kosminsky; Mauricio e Rosa Kosminsky; e uma de Abrahão quando jovem. Os avós de Abrahão conservavam os traços da antiga Europa Oriental, ela com a cabeça coberta com um pano branco, cujas pontas eram amarradas atrás do pescoço e ele com um chapéu preto na cabeça e uma longa barba branca. Mauricio e Rosa já haviam incorporado alguns traços do Brasil, ele com a barba feita e sem chapéu, ela com a cabeça descoberta, vestida simplesmente.

Expliquei que teria sido muito difícil para nosso pai ter se casado com Auta, a mãe de meu irmão Adauto. Os dois menores de idade e Abrahão com todo o peso da tradição de ser filho e neto de imigrantes. Casar-se com uma pessoa não-judia implicava naquela época na quebra das relações familiares. Toda a família judia sentaria Shiva ${ }^{6}$, ou seja, estaria de luto por aquele que rompeu com a tradição, a religião e consequentemente com os laços familiares.

À noite, depois das nossas conversas, com Nete geralmente ao lado, eu dava um beijinho no rosto do Adauto todo enroladinho, encolhido em um canto da cama e em Dalva, sempre bonitinha com o rostinho corado. Queria muito que o frio que Adauto sentia passasse e que ele se sentisse melhor.

Segundo Nete, Abrahão não deveria saber que tinha um filho. Os seus pais sabiam e teriam ocultado essa informação. Mas, como disse ela, "não interessa, o importante é que estamos todos juntos." A minha nova e querida família não pareceu se interessar pelo judaísmo. Mas mostrou interesse pela origem da família na Bessarábia, hoje Moldava.

Antes da minha viagem, Nete e Pat queriam saber o que eu não poderia comer. Disse que apenas não poderia comer sementes duras, só isso. E do que eu gostava? De tudo, a começar pela jaca, fruta difícil de encontrar fora do Nordeste. Acho que não preciso dizer que foi um festival de comida. 
Estávamos sempre em volta da mesa. Ah! Que delícia é um café feito com coador de pano! Os bolos de aipim, macaxeira como é conhecida no Sudeste do Brasil, que elas compravam. Até um bolo de puba ${ }^{7}$ Nete encomendou e foi buscar no dia seguinte. O feijão com arroz e farinha de mandioca..., para que melhor? As costelas de porco e de boi, o toicinho de porco frito, o carneiro, a carne-de-sol. Tudo Val, a cozinheira, preparava com todo o capricho batendo os temperos no pilão. E os pães de polvilho? Pareciam pães de queijo, mas eram feitos unicamente de polvilho. As verduras: maxixe, chuchu e batata cozidos com um tempero muitíssimo bom! A jaca que Ari comprou no Ceasa, o doce de figo que ela deixou pronto para minha chegada. A rapadura cortadinha em um vidro fechado com tampa por causa das formigas.

Teve as comilanças nas casas dos sobrinhos: uma bacalhoada na de Toni Zé e Petta, um almoço de sarapatel feito pela sogra da Pat, e um salmon acompanhado de ravioli de carne de sol na casa nova do Ivanildo e da Ari.

As visitas que recebi... Dalva cresceu em uma família de oito mulheres, contando com ela, e mais dois homens. Das quatro que estão vivas, só não veio uma "porque estava na roça". As visitas dos primos dos meus sobrinhos. A companhia de Manu, a cachorra dálmata que não deixava pessoa alguma chegar perto de Adauto e Dalva, mas que ficou minha amiga.

Foi uma felicidade sem tamanho. Com esses cuidados e mimos, senti-me muito feliz, muito amada e muito bem-acolhida. Uma semana com a intensidade de quase uma vida para se colocar em dia. Minhas doenças gastro-intestinais e a depressão desapareceram como por milagre. Nunca tinha tido uma família como aquela.

Nos comparamos. Medimos nossa aparência. O que tínhamos fisicamente em comum? Uma marquinha no queixo, o formato do rosto que eu e o Adauto compartilhávamos, o perfil meu e da Pat, a Nete parecida com a Tia Bela e assim por diante. Também as diferenças, como disse uma das irmãs de Dalva: "ela é forte (gordinha) e o Adauto é magrinho".

Os meus irmãos Adauto e Dalva e mais os sobrinhos se juntaram e compraram um lindo quadro sobre a caatinga de um famoso pintor da cidade, cuja fama já havia atingido outros países. Todos os presentes dos sobrinhos foram muito preciosos pois vinham carregados de carinho. A despedida foi muito difícil. Sinto muito a falta dos sobrinhos e dos sobrinhos-netos. Penso sempre no Adauto e na Dalva e na vontade que tenho de dar boa noite para eles, sentar na cadeira perto, conversar e depois dar os beijos de boa-noite nos dois.

Adauto completou meus pensamentos: "agora estou bem, consegui o que estava faltando na minha vida". 


\section{Notas}

1 - Mensch, original do lídich, a língua falada pelos judeus da Europa Oriental antes do seu quase total extermínio pelos nazistas.

2 - Maurice (Zvi) von Hirsch (1831 - 1896) foi um banqueiro e filantropo judeu-alemão que montou fundações de caridade para promover a educação judaica e melhorar a sorte dos oprimidos judeus europeus. Ele foi o fundador da Jewish Colonization Association, que financiou o estabelecimento de colonias agrícolas.

3 - Palavra í́diche para ataques promovidos pela população local não-judia e pelos cossacos que atacavam os judeus, matando e destruindo suas casas e meios de vida. Os pogroms ocorreram no século XIX e início do século XX, no antigo Império Russo.

4 - Cossacos, refere-se àqueles que serviam na cavalaria do exército do czares e promoviam os pogroms.

5 - Shabat comemora a criação por Deus do Universo, quando no sétimo dia ele descansou. É observado do entardecer da sexta até o entardecer do sábado.

6 - Shiva é a semana de luto observada devido à perda de parentes bem próximos. O ritual é observado como "sentar shiva." Imediatamente depois do enterro, os membros da família se reúnem na casa do (a) falecido (a) para receberem as visitas.

7 - Bolo de mandioca. 